\title{
Reducing the burden of regular indwelling urinary catheter changes in the catheter clinics: the opinion of patients and relatives on the practice of self-catheterization
}

\author{
This article was published in the following Dove Press journal: \\ Patient Preference and Adherence \\ 2 September 2014 \\ Number of times this article has been viewed
}

\author{
Ikenna I Nnabugwu \\ Emeka I Udeh \\ Oghenekaro A Enivwenae \\ Fred $O$ Ugwumba \\ Oyiogu F Ozoemena
}

Urology Unit, Department of Surgery, University of Nigeria Teaching

Hospital, Enugu, Nigeria
Correspondence: Ikenna I Nnabugwu Urology Unit, Department of Surgery, University of Nigeria Teaching Hospital, Ituku-Ozalla, PMB 00129 , 40000I Enugu State, Nigeria Email iinnabugwu@yahoo.com
Background: Clean intermittent self-catheterization is accepted worldwide as a standard of care for patients with long-standing need for urinary bladder decompression. Evidence of its routine practice in our low-resource setting is lacking, leading to increasing number of patients with a long-standing indwelling urinary catheter.

Objective: To seek the opinion of patients already using indwelling catheters regarding the practice of self-catheterization.

Patients and methods: Over a 4-month period, the opinion of every patient and patient's relative that attended the regular urinary catheter clinic was sought using an intern-administered questionnaire. The data was analyzed using SPSS version 20.

Results: A total of 108 patients completed the questionnaire. Age range was 16-100 years with a mean of $62.2 \pm 15.5$ years. Only $30.5 \%$ of the patients had formal education beyond the primary level. The median cost for change of the indwelling catheter was 1,325 naira ( $\$ 8.28$ US) with a range of 500-4,000 naira (\$3.13-\$25 USD). Analysis showed that: $70.8 \%$ of patients aged under 60 years $/ 60.6 \%$ of those with formal education beyond primary level $/ 61.9 \%$ of those wearing catheters for $<3$ months would give consent for training in self-catheterization. Higher cost of catheter change did not influence the decision to consider self-catheterization. Of the 59 patient relatives who completed the questionnaire, $63 \%$ of those younger than 50 years old and $69.2 \%$ of those with tertiary education would be willing to undertake training to administer self-catheterization.

Conclusion: A select group of patients and accompanying relatives in our low-resource setting are willing to learn and practice self-catheterization.

Keywords: self-catheterization, patients' opinion, indwelling catheter

\section{Introduction}

Urethral catheterization, one of the earliest urological procedures known to man, remains an essential component of the management of patients with lower urinary tract disorders. ${ }^{1}$ In medical conditions that will need prolonged catheterization of an otherwise stable patient as seen in prostate enlargement, urethral stricture, and neurogenic bladder, self-catheterization is the gold standard - provided it is accepted by the patient, taught by the professional, and clearly understood by the patient. ${ }^{2}$ A relative of the patient can also be trained and authorized, with the patient's consent to administer clean catheterization.

In an intermittent catheterization, the catheter is removed immediately after draining the urinary bladder. Indwelling catheters (usually Foley catheters) are anchored in 
place for a specific period of time before changing. ${ }^{3}$ Though indwelling catheters are associated with an increased risk of urinary tract infections, encrustations and stone formation, painful bladder spasms, and catheter bypassing, these are related mainly to the duration of catheterization. ${ }^{3,4}$ However, complications, such as undue pain during catheterization, urethral bleeding, and failure of catheterization, are related to the technique of catheterization. Proper teaching and training of motivated patients and caregivers will ensure that the risk of this group of complications during self-catheter change is reduced to a minimum. ${ }^{5}$

Bladder outlet obstruction is a common reason for insertion of indwelling urethral catheter as an outpatient. ${ }^{6}$ The catheter is inserted to relieve the obstruction, to ameliorate suffering, and to preserve the upper urinary tract function pending the confirmation of the diagnosis and the institution of the definitive treatment. In a resourcepoor economy, quite a good number of the patients remain on indwelling catheters longer than indicated, because the patients are unable to afford the definitive treatment, or the health facility lacks the required equipment and expertise for prompt definitive treatment. ${ }^{6,7}$ Relegation to the regular change of catheters becomes inevitable. The patient therefore begins regular hospital visits, accompanied usually by a first-degree relative. The burden of this phase of treatment could be enormous. ${ }^{6}$

Clean intermittent self-catheterization (CISC) has been routinely practiced, in the more advanced economies, by adult male patients, as well as by care providers who may not necessarily be medical doctors or nurses. ${ }^{8-10}$ Evidence of its routine practice in our resource-poor setting is lacking. After proper lubrication, a noncoated catheter can be inserted much the same manner a hydrophilic catheter is inserted, with no significant difference in complication rates. ${ }^{11}$

Based on the existing patient's therapeutic education concept of self-catheterization, ${ }^{2}$ this study focuses on the opinion of the adult male patients who had received regular indwelling catheter changes in our catheter clinic, with the idea of training for catheter changes by self, or by a relative.

\section{Materials and methods}

This study was conducted in the catheter clinic at the University of Nigeria Teaching Hospital, Enugu state, southeastern Nigeria. Usually, 35-55 patients visited the clinic weekly for a change of catheter from January 2010-December 2011; three to seven were new patients. In all, $\sim 450$ patients were seen at least once in the catheter clinic in the year 2011. So, adopting a confidence interval of 10 and a confidence level of
$95 \%$, we worked out a sample size of 79 patients for the study (Power Analysis and Sample Size software, PASS 13).

From May 2013-August 2013, a period of 4 months, the opinion of every patient that attended the catheter clinic of the urology unit was obtained once, using an intern-administered questionnaire.

After the catheter change session, the intern doctor read and explained in the native language to the patient and the patient's relative each parameter contained in the questionnaire. Information obtained was: the age of the patient; highest level of formal education; the duration of catheterization; average cost of each catheter-change procedure (inclusive of transport fare); and opinion about catheter change by self or by relative after appropriate teaching and training. The questionnaire was administered to patients who attended the clinic to change indwelling catheters, but not to those whose urinary catheters were being inserted or changed for the first time. Data analysis was completed using SPSS version 20. The chi-squared test was used for parametric tests; The Yates' correction for continuity (or Yates' chi-squared test) is employed when the expected cell count in a $2 \times 2$ contingency table is less than 5 . The level of significance was set at a two-tailed $P$-value of $<0.05$.

\section{Results}

A total of 108 patients were seen within the study period. Table 1 shows the age distribution of the patients. Most of them were over 60 years old, with an average age of $66.2 \pm 15.5$ years and a range of 16-100 years.

The patients were mostly farmers $(34$ [31.5\%]) and retired civil servants $(20[18.5 \%])$. Only nine $(8.3 \%)$ had a tertiary education. Forty five (41.7\%), representing the majority, had a primary education, while $24(22.2 \%)$ had a secondary education. Thirty patients $(27.8 \%)$ had no formal education. Also, 71 patients $(65.7 \%)$, representing the majority, had urethral catheterization, while 37 (34.3\%) had suprapubic catheterization. Table 2 shows the primary diagnosis of the patients.

The total cost of catheterization, including the cost of transportation to and from the hospital, was documented for 102 patients. It ranged from 500 naira (\$3.13 US) to 4,000 naira (\$25 US), with a median cost of 1,325 naira (\$8.28 US).

Table I Age distribution of patients

\begin{tabular}{ll}
\hline Age (years) & Frequency, $\mathbf{n}(\%)$ \\
\hline$<40$ & $8(7.4)$ \\
$40-60$ & $16(14.8)$ \\
$>60$ & $84(77.8)$ \\
Total & $108(100.0)$ \\
\hline
\end{tabular}


Table 2 Primary diagnosis

\begin{tabular}{ll}
\hline Diagnosis & Frequency, $\mathbf{n}$ (\%) \\
\hline Benign prostatic hyperplasia & $72(66.7)$ \\
Urethral stricture & $19(17.6)$ \\
Carcinoma of prostate & $15(13.9)$ \\
Neurogenic bladder & $1(0.9)$ \\
Neglected posterior urethral valve & $\mathrm{I}(0.9)$ \\
Total & $108(100.0)$ \\
\hline
\end{tabular}

Also, 76 patients (70.4\%), representing the majority, were already on a catheter for $>6$ months, while $21(19.4 \%)$ had a catheter in use for $<3$ months. Eleven patients (10.2) had a catheter in use for $\sim 3-6$ months.

The majority of these patients $(60 ; 59.6 \%)$ came for change of catheter every 3 weeks. Also, 29 patients (28.7\%) came every 4 weeks, while 12 patients (11.9\%) every 2 weeks. In seven patients $(6.5 \%)$, there was no pattern.

Figure 1 shows each patient's opinion to the question: "based on all you have seen so far, do you think you can change your catheter yourself?" Figure 2, on the other hand, shows the response to the question: "if you are trained, do you think you can change your catheter yourself?" Only 13.89\% answered "yes" to the initial question, while $39.81 \%$ said "yes" to the follow-up question.

When asked if they would allow a relative to change their catheters, three patients $(2.8 \%)$ were indifferent. Also, $58(53.7 \%)$ said no; and 47 (43.5\%) said yes. The majority (65 [60.2\%]), however, agreed that the catheter can be changed by a relative if that relative has been adequately trained. Also, 43 (39.9\%) said "no" or were indifferent. In addition, 59 patient relatives (23 males [39.0\%] and 36 females [61.0\%]), were also interviewed about their opinion on home catheter change. This information is

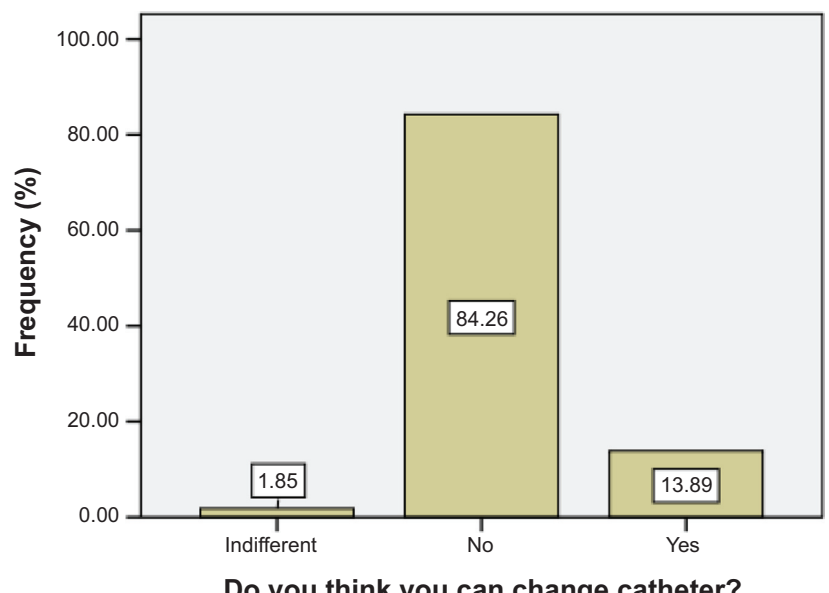

Figure I Response of patients when asked if they can change their catheters.

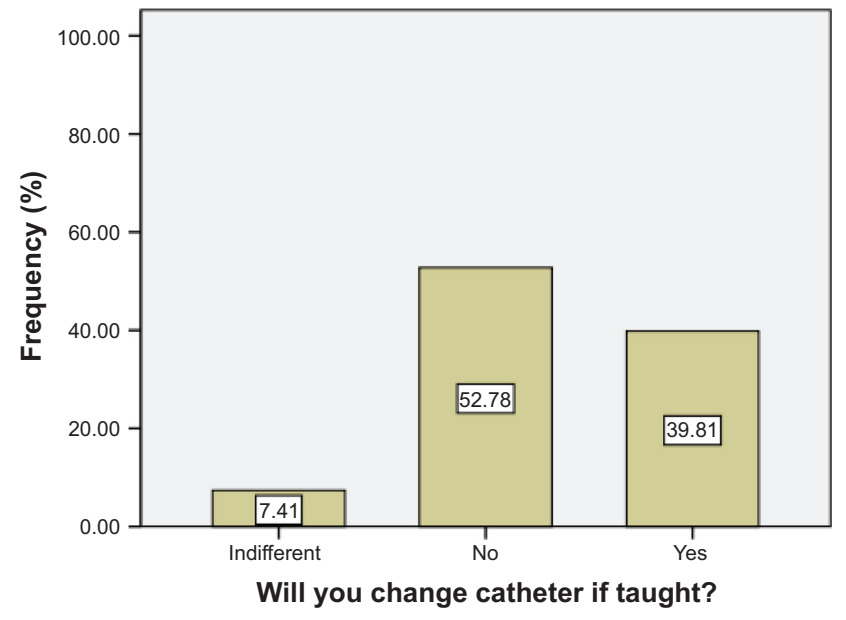

Figure 2 Response of patients when asked if they would change their catheters after training.

presented in Table 3. The majority of the relatives (54.2\%) felt it was easy to learn, while 18 (30.5\%) felt it was difficult to learn. Five (8.5\%) felt it was impossible to learn. The statistically significant factors affecting opinion on self-catheter change are presented in Table 4.

\section{Discussion}

The catheter clinic, as it is commonly referred to, is a busy clinic in our setting. ${ }^{6}$ Most of its attending patients are sequestered there because of lack of funds to access the required definitive treatment, and - in the absence of health insurance - the end to this phase of treatment is not in sight. Others are there to allow time for the stabilization of the renal status, optimization of the cardiopulmonary status, or as part of terminal care. The patient's therapeutic education proposed by Haute Autorité de Santé (French National Authority for Health) is accepted as a way to manage patients with chronic disease conditions with the aim of improving quality of life at an acceptable cost. ${ }^{2}$ The practice of clean intermittent self-catheterization, as popularized by Lapides et $\mathrm{al}^{12}$ is still in its rudimentary stage in our low-resource setting; very little is available in literature from this low-resource setting as well. The cohort of patients attending the catheter clinic was chosen,

Table 3 Response of patients' relatives when asked if they can change catheter

\begin{tabular}{ll}
\hline Do you think you can change catheter? & Frequency, n (\%) \\
\hline Yes & $32(54.2)$ \\
No & $22(37.3)$ \\
Indifferent & $5(8.5)$ \\
Total & $59(100.0)$ \\
\hline
\end{tabular}


Table 4 Factors affecting opinion on home catheter change

\begin{tabular}{|c|c|c|c|c|}
\hline \multicolumn{5}{|l|}{ Do you think you can change catheter? } \\
\hline Factors & Yes, n (\%) & No/indifferent, n (\%) & Total & $P$-value \\
\hline Age $\leq 60$ years, $(\mathrm{N}=108)$ & $17(70.8)$ & $7(29.2)$ & 24 & $0.000 *$ \\
\hline At least secondary education, $(\mathrm{N}=108)$ & $20(60.6)$ & $13(39.4)$ & 33 & $0.003 *$ \\
\hline Catheter use $<3$ months, $(\mathrm{N}=108)$ & $13(61.9)$ & $8(38.1)$ & 21 & $0.02 I^{*}$ \\
\hline $\begin{array}{l}\text { Cost of change of catheter }>2,000 \text { naira } \\
(\$ 12.50 \text { US), }(\mathrm{N}=102)\end{array}$ & $3(16.7)$ & $15(83.3)$ & 18 & $0.031 *$ \\
\hline Patient relative (changer) $<50$ years, $(\mathrm{N}=59)$ & $29(63.0)$ & $17(37.0)$ & 46 & $0.011 *$ \\
\hline $\begin{array}{l}\text { Patient relative (changer) with tertiary } \\
\text { level of education, }(\mathrm{N}=59)\end{array}$ & $18(69.2)$ & $8(30.8)$ & 26 & $0.040^{*}$ \\
\hline
\end{tabular}

Note: $* P<0.05$ is statistically significant.

because it was thought that their opinion on the practice of self-catheter change would be influenced by their practical experience from the catheter clinic. Also, 76 respondents (70.4\%) had been on indwelling catheters for $>6$ months, yet more than $84.3 \%$ of all patients had surgically correctable disease conditions.

To effectively practice patient's therapeutic education, willingness to learn must be established. Overall, 39.81\% of patients said "yes" to self-catheterization after being put through the training. About $22.2 \%$ of respondents were 60 years or younger; $70.8 \%$ of these were of the opinion that given the requisite training, they would practice self-catheter change. This number is statistically significant.

Of the patients older than 60 years ( $77.8 \%$ of all patients), there was no significant difference in opinion on whether they would accept to practice self-catheter change. Several studies from centers that practice CISC have shown that a younger age also positively influenced adherence to CISC..$^{13,14}$ Similarly, in reviewing the success rate of intermittent self-catheterization among 309 patients with a mean age of 62 years, Parsons et al recorded a success rate of $86 \%$ for patients younger than 65 years and $82 \%$ for those 65 years and older. ${ }^{15}$

Among the respondents with at least a secondary level of education, $61 \%$ thought they could change their catheters themselves after adequate training, while 39\% thought they could not. This difference is statistically significant and may be explained by the increased confidence in one's abilities conferred by formal education. If given the opportunity to learn and practice self-catheterization, the younger age group - with at least a secondary level of education - who constitutes the mainstay of the economy, will have improved self-esteem, be more available at work, and more productive.

Interestingly, the higher cost of catheter change did not influenced opinions toward "yes." In addition, $83 \%$ of the patients who spent more than 2,000 naira ( $\$ 12.50 \mathrm{US}$ ) per catheter change session would not accept the responsibility of changing their catheters themselves - despite training.

Twenty one patients (19.4\%) had spent 3 months or less in the catheter clinic, and $61.9 \%$ of these were of the opinion that with proper training, they could change their catheters themselves. On the contrary, among the $80.6 \%$ of patients attending the catheter clinic for more than 3 months, there was no significant difference in opinion on self-catheter change. The reason for this pattern is not clear, as it would have been easier to appreciate that the longer one visits the catheter clinic, the more familiar the process seems.

An analysis of the opinions of accompanying relatives who could be given this responsibility of self-catheterization ${ }^{16}$ reveals that the younger age ( $<50$ years) and tertiary level of formal education significantly influenced the acceptance of the responsibility.

A major limitation to this study is that there was no attempt to objectively assess the intelligence and the cognitive function of the respondents. However, each respondent was allowed time to consider each item in the questionnaire and understand it before responding. In conclusion, this cohort of patients represents, in our environment, a group of nonmedical personnel that is most knowledgeable in urinary catheterization. The opinion expressed in this study has demonstrated that in a resource poor economy like Nigeria, younger and educated patients and relatives are likely to consent to training on self-catheterization with the view to reducing the burden of regular catheter changes in the weekly catheter clinics of the various urology units. We advocate for the setting up of catheter units to undertake training of appropriately selected patients and caregivers on CISC. The modality and content of such trainings are to be worked out by an appropriate technical committee with reference to the confounding factors.

\section{Disclosure}

The authors report no conflicts of interest in this work. 


\section{References}

1. Di Benedetto P. Clean intermittent self-catheterization in neuro-urology. Eur J Phys Rehabil Med. 2011;47(4):651-659.

2. Le Breton F, Guinet A, Verollet D, Jousse M, Amarenco G. Therapeutic education and intermittent self-catheterization: recommendations for an educational program and a literature review. Ann Phys Rehabil Med. 2012;55(3):201-212.

3. Cochran S. Care of the indwelling urinary catheter: is it evidence based? $J$ Wound Ostomy Continence Nurs. 2007;34(3):282-288.

4. van Achterberg T, Holleman G, Cobussen-Boekhorst H, Arts R, Heesakkers J. Adherence to clean intermittent self-catheterization procedures: determinants explored. J Clin Nurs. 2008;17(3):394-402.

5. Wyndaele JJ. Complications of intermittent catheterization: their prevention and treatment. Spinal Cord. 2002;40(10):536-541.

6. Ikuerowo SO, Ogunade AA, Ogunlowo TO, Uzodimma CC, Esho JO. The burden of prolonged indwelling catheter after acute urinary retention in Ikeja - Lagos, Nigeria. BMC Urol. 2007;7:16.

7. Okeke LI, Aisuodionoe-Shadrach OI. Self-reported quality of life measures of patients with benign prostatic hyperplasia on indwelling urethral catheters. African Journal of Urology. 2006;12(1):15-23.

8. Getliffe K, Fader M, Allen C, Pinar K, Moore KN. Current evidence on intermittent catheterization: sterile single-use catheters or clean reused catheters and the incidence of UTI. $J$ Wound Ostomy Continence Nurs. 2007;34(3):289-296.

9. Patel MI, Watts W, Grant A. The optimal form of urinary drainage after acute retention of urine. BJU Int. 2001;88(1):26-29.
10. Ghalayini IF, Al-Ghazo MA, Pickard RS. A prospective randomized trial comparing transurethral prostatic resection and clean intermittent self-catheterization in men with chronic urinary retention. BJU Int. 2005;96(1):93-97.

11. Bermingham SL, Hodgkinson S, Wright S, Hayter E, Spinks J, Pellowe C. Intermittent self catheterisation with hydrophilic, gel reservoir, and non-coated catheters: a systematic review and cost effectiveness analysis. BMJ. 2013;346:e8639.

12. Lapides J, Diokno AC, Silber SJ, Lowe BS. Clean intermittent selfcatheterization in the treatment of urinary tract disease. J Urol. 1972; 107(3):458-461.

13. Seth JH, Haslam C, Panicker JN. Ensuring patient adherence to clean intermittent self-catheterization. Patient Prefer Adherence. 2014;8: 191-198.

14. Girotti ME, MacCornick S, Perissé H, Batezini NS, Almeida FG. Determining the variables associated to clean intermittent self-catheterization adherence rate: one-year follow-up study. Int Braz J Urol. 2011; 37(6):766-772.

15. Parsons BA, Narshi A, Drake MJ. Success rates for learning intermittent self-catheterisation according to age and gender. Int Urol Nephrol. 2012;44(4):1127-1131.

16. Robinson J. Insertion, care and management of suprapubic catheters. Nurs Stand. 2008;23(8):49-56; quiz 58
Patient Preference and Adherence

\section{Publish your work in this journal}

Patient Preference and Adherence is an international, peer-reviewed, open access journal that focuses on the growing importance of patient preference and adherence throughout the therapeutic continuum. Patient satisfaction, acceptability, quality of life, compliance, persistence and their role in developing new therapeutic modalities and compounds to optimize

\section{Dovepress}

clinical outcomes for existing disease states are major areas of interest for the journal. This journal has been accepted for indexing on PubMed Central. The manuscript management system is completely online and includes a very quick and fair peer-review system, which is all easy to use. Visit http://www. dovepress.com/testimonials.php to read real quotes from published authors. 